\title{
Activation of G-protein Coupled Estradiol Receptor 1 in the Dorsolateral Striatum Enhances Motivation for Cocaine and Drug-Induced Reinstatement in Female Rats
}

Jacqueline Quigley ( $\nabla$ jacqueq@umich.edu )

University of Michigan https://orcid.org/0000-0001-9227-6220

Molly K. Logsdon

University of Michigan

Brianna C. Graham

University of Michigan

Kendra G. Beaudoin

University of Michigan

Jill B Becker

University of Michigan

\section{Research}

Keywords: GPER1, dorsolateral striatum, sex differences, motivation, addiction, cocaine

Posted Date: April 8th, 2021

DOI: https://doi.org/10.21203/rs.3.rs-382786/v1

License: (a) (1) This work is licensed under a Creative Commons Attribution 4.0 International License.

Read Full License

Version of Record: A version of this preprint was published at Biology of Sex Differences on August 14th, 2021. See the published version at https://doi.org/10.1186/s13293-021-00389-w. 


\section{Abstract}

\section{Background}

Estradiol potentiates drug-taking behaviors, including motivation to self-administer cocaine and reinstatement of drug-seeking after extinction in females, but not males. The dorsolateral stratum (DLS) is a region of the brain implicated in mediating drug-seeking behaviors and more specifically, is a target brain area to study how estradiol regulates these behaviors. The estradiol receptors $a, \beta$, and G-protein coupled estradiol receptor 1 (GPER1) are all present in the DLS. In this study the effects of activating GPER1 in the DLS on drug-seeking are investigated.

\section{Methods}

Gonad-intact male and female rats were trained to self-administer cocaine $(0.4 \mathrm{mg} / \mathrm{kg} / \mathrm{inf})$ on an fixedratio 1 schedule of reinforcement. For four weeks, animals underwent testing on a progressive ratio schedule of reinforcement to determine their motivation to attain cocaine. Halfway through progressive ratio testing, a selective agonist targeting GPER1 (G1) was administered intra-DLS to determine the contribution of GPER 1 activation on motivation for cocaine. The effects of intra-GPER1 activation on drug-induced reinstatement after extinction was subsequently determined.

\section{Results}

Activation of GPER1, via G1 administration intra-DLS potentiated females' motivation to self-administer cocaine. There was no effect of prior $\mathrm{G} 1$ treatment on extinction of cocaine-taking in females, however, $\mathrm{G} 1$ treatment resulted in greater drug-induced reinstatement $(10 \mathrm{mg} / \mathrm{kg}$ cocaine, i.p.). There were no effects of intra-DLS GPER1 activation observed on motivation for cocaine or cocaine-induced reinstatement of responding in males.

\section{Conclusions}

These results support the conclusion that activation of GPER1 in the DLS enhances cocaine seeking behaviors for female, but not male rats.

\section{Highlights}

- Selective stimulation of the membrane estradiol receptor, GPER-1, in the dorsolateral striatum enhances motivation to self-administer cocaine in female rats.

- Selective stimulation of the membrane estradiol receptor, GPER-1, in the dorsolateral striatum enhances cocaine-induced reinstatement in female rats.

- GPER-1 stimulation in the dorsolateral striatum does not alter self-administration of cocaine or reinstatement of responding for cocaine in male rats. 


\section{Introduction}

The prevalence of adults who will develop a substance use disorder (SUD) is nearly $10 \%$, although many more will recreationally use drugs at some point in their lifetime (Grant et al. 2016). Many factors contribute to individual differences in escalation of drug taking behavior. Biological sex is one component that affects individual differences in vulnerability to develop a SUD to psychostimulants (Quigley et al. 2021). For example, women report greater craving for cocaine, escalate cocaine use more rapidly, and have shorter cocaine-free periods compared to men (Westermeyer et al. 1997; Elman et al. 2001). Women also have greater incidence of relapse, possibly due to stress-induced drug seeking that occurs more in women than men (McKay et al. 1996; Back et al. 2005).

There are sex differences in rodent models of addiction that are comparable to what is reported in the clinical literature (Becker and Koob 2016). Female rats acquire cocaine self-administration more rapidly than males do, are more motivated to obtain cocaine, and take longer to extinguish cocaine seeking behavior, compared to males (Lynch and Carroll 1999; Lynch 2008; Roth and Carroll 2004; Kippin et al. 2005). In females, but not males, the presence of estradiol (E2) enhances sensitization to cocaine, acquisition and maintenance intake, and reinstatement of cocaine-taking after extinction (Zhao and Becker 2010; Jackson et al. 2006; Martinez et al. 2016; Doncheck et al. 2018). Together, these data support a role for E2 in increasing vulnerability to addiction-like behaviors in female, but not male rodents.

Recent evidence supports a modulatory role of E2 on males' preference for cocaine. Specifically, activation of the E2 receptor subtype, G-protein coupled estradiol receptor 1 (GPER1), decreases conditioned place preference for cocaine and morphine in male rodents (Quigley and Becker 2021; Sun et al. 2020). As mentioned above, no studies thus far have determined an effect of E2 treatment on males' self-administration of cocaine, but this could be because prior studies have not investigated the contribution of individual ER subtypes to drug self-administration in either sex. The E2 receptor (ER) subtypes, ERa, ER $\beta$, and GPER1 are all present in the dorsal striatum (Quigley and Becker 2021). Given the recent evidence implicating GPER1 as an important neuronal target that mediates the rewarding properties of cocaine in males (Quigley and Becker 2021), this study was designed to determine whether GPER1 activation within the dorsolateral striatum (DLS) modulates motivation for cocaine selfadministration in either sex. The current study used a progressive ratio self-administration paradigm to determine the contribution of GPER1 activation on motivation, extinction and reinstatement of cocaineseeking in both female and male rats.

\section{Materials And Methods}

\section{Animals}

A total of 25 male and 26 female gonad-intact Sprague-Dawley rats were used in this experiment. Animals were ordered from Charles River Breeding Laboratory (Portage, MI, USA) and were approximately 
75 days old on arrival. Animals were maintained on a 14:10 light/dark cycle in a temperature-controlled climate of $72^{\circ} \mathrm{F} \pm 2^{\circ} \mathrm{F}$, in ventilated laboratory cages. Animals were initially housed in same-sex pairs until undergoing surgery and subsequently housed individually. Rats had ad libitum access to water and phytoestrogen-free rat chow (2017 Teklad Global, 14\% protein rodent maintenance diet, Harlan rat chow; Harlan Teklad, Madison, WI, USA). All animals were weighed daily to determine good health and females were also vaginally lavaged daily to track their estrous cycle. All animal care and experimental procedures were carried out in accordance with the National Institutes of Health guidelines on laboratory animal use and care, using a protocol approved by University of Michigan Institutional Use and Care of Animals Committee.

\section{Stereotaxic Surgery and Treatment Stylets}

One week after arriving in the laboratory, rats underwent surgery for the implantation of bi-lateral guide cannula (purchased from P1 Technologies) aimed at the DLS (AP: +0.4 ML: +/-3.6 DV: -4.0). On the day of surgery, rats were injected with carprofen $(5 \mathrm{mg} / \mathrm{kg} \mathrm{s.c.)}$ and 30 minutes later were anesthetized with ketamine (50 mg/kg i.p.) and dexmedetomidine $(0.25 \mathrm{mg} / \mathrm{kg}$ i.p.), then prepared in a stereotaxic frame. At the conclusion of the surgery, animals received atipamezole hydrochloride $(0.5 \mathrm{mg} / \mathrm{kg}$ i.p.) and $3 \mathrm{ml} 0.9 \%$ saline (s.c.). Every 24 hours for three days post-surgery, they were given carprofen ( $5 \mathrm{mg} / \mathrm{kg}$ s.c.) prophylactically for post-operative pain then monitored for an additional seven days.

During surgery, 33-gauge solid stylets were inserted into the 26-gauge hollow guide cannula that were fixed on the animal's heads. These stylets were flush with the bottom of the guide cannula and did not protrude into the brain. Treatment stylets protruded from the guide cannula by $1 \mathrm{~mm}$ and delivered treatment directly into the DLS. These stylets were prepared as previously described (Becker et al. 1987). In order to insert stylets, rats were briefly anesthetized with $5 \%$ isoflurane.

Control animals received 100\% cholesterol (CHOL) and experimental animals received $90 \% \mathrm{CHOL}: 10 \% \mathrm{G} 1$ (selective GPER1 agonist). Pharmacological drugs were obtained from the following sources: Cholesterol (Santa Cruz Biotechnology, purity $\geq 92 \%$ ); G1 (Cayman Chemical, purity $\geq 98 \%$ ).

\section{Catheter Surgery}

One week after undergoing stereotaxic surgery, animals were fitted with indwelling jugular catheters that connected to a dorsal facing external port (Cummings et al. 2011). On the day of surgery, animals received carprofen ( $5 \mathrm{mg} / \mathrm{kg}$ s.c.) and 30 minutes later were anesthetized with $5 \%$ isoflurane in oxygen. Beginning two days after surgery and continuing everyday thereafter, catheters were flushed with $0.2 \mathrm{ml}$ of $(3 \mathrm{mg} / \mathrm{ml})$ and heparin $(20 \mathrm{U} / \mathrm{ml})$ to prevent clotting and infection, respectively. Prior to the beginning of each cocaine self-administration sessions, the catheters were also flushed with $0.1 \mathrm{ml}$ of sterile saline. Every 24 hours for three days post-surgery, animals were given carprofen ( $5 \mathrm{mg} / \mathrm{kg} \mathrm{s.c.)} \mathrm{prophylactically}$ for post-operative pain. Animals were monitored for an additional seven days before beginning selfadministration behavioral testing.

\section{Cocaine Self-Administration Procedures}




\section{Chamber}

Cocaine self-administration was performed in standard operant chambers (Med Associates, Inc., Georgia, VT, USA). Rats were able to move freely in the testing environment while being connected to an infusion syringe via their dorsal port. A house light turned on inside the chamber to signify the start of each selfadministration session. Each chamber was also equipped with two nose poke ports. The active port had an illuminated light, while the other port had no light and was therefore "inactive". A nose poke response in the active port results in an intravenous $50-\mu$ infusion of $0.4 \mathrm{mg} / \mathrm{kg} /$ infusion cocaine $\mathrm{HCl}$ delivered over 2.8 seconds and there was no consequence of poking in the inactive port.

\section{Training}

Animals were tested 5 days a week and were off for 2 days each week. During week one, rats were allowed to nose poke to self-administer cocaine on a fixed-ratio 1 schedule of reinforcement. Under this schedule, a response into the active port resulted in one infusion of cocaine followed by a 5-second timeout period of drug unavailability. If an animal nose poked during a timeout period, the nose poke was recorded but the animal did not receive an infusion of cocaine. Each training session was three hours long or until an animal received a maximum of 15 infusions of cocaine. If an animal did not meet the 15infusion threshold, they were given the remaining infusions one minute apart.

\section{Progressive Ratio}

For four consecutive weeks thereafter, animals underwent a progressive ratio schedule of reinforcement that escalated through an exponential series: $1,3,6,9,12,17,24,32,42,56,73,95,124,161,208, \ldots$ (Richardson and Roberts 1996). While the number of nose pokes required increased exponentially, the consequence remained at a single cocaine infusion. The daily session was terminated when 1 hour elapsed without the animal having earned the next infusion, termed the animal's "breaking point". Otherwise, the session was terminated at the 4 -hour mark and the breaking point reached up to that point was recorded.

During weeks 3 and 4 of progressive ratio self-administration, animals received either 10\% G1 (90\% cholesterol; $\mathrm{CHOL}$ ) or $\mathrm{CHOL}$ intra-DLS (see Table 1. for treatment condition assignments). Treatment conditions were assigned so that the average breaking point between each group did not differ for weeks 1 and 2 of progressive ratio testing. Treatment stylets were inserted after the final self-administration session of week 2 and remained through week 4, except for when they were briefly replaced for new stylets between weeks 3 and 4 , in order to maintain stable dose. Treatment stylets were removed at the conclusion of week 4 .

\section{Extinction and Reinstatement}

During week 5, rats underwent 1-hour extinction training twice per day for a total of 10 extinction training sessions in five days. Chamber conditions (i.e., house light and nose port light) were the same as during 
progressive ratio testing, except that rats did not receive an infusion of cocaine after nose poking. The rate of extinction was calculated as the difference between activate and inactive nose pokes per session.

New treatment stylets were introduced after the final extinction session and treatment conditioned were assigned to control for prior $\mathrm{G} 1 / \mathrm{CHOL}$ treatment (see Table 2. for treatment condition assignments). On day one of week 6 , animals were tested for drug-induced reinstatement. Similar to extinction, no consequence resulted from nose poking in either port. At the start of the self-administration session, each animal received a $10 \mathrm{mg} / \mathrm{kg}$ i.p. injection of cocaine.

\section{Statistics}

All statistical analyses were performed using GraphPad Prism v8.0 and IBM SPSS Statistics v27.0. Data were analyzed for normality using the Shapiro-Wilk normality test. Effect sizes are reported as partial eta squared $\left(n^{2} p\right)$. For breaking point data, a three-way repeated measures ANOVA was performed (sex $x$ treatment condition $x$ timepoint). To analyze extinction rates between groups, a two-way ANOVA was performed (sex x prior treatment condition). To analyze reinstatement rates between groups, a two-way repeated measure ANOVA was performed (sex $x$ treatment). In the case of a significant interaction within any ANOVA analysis, a Bonferroni multiple comparison test determined if there were significant group differences. Females' breaking point data were analyzed by phase of their estrous cycle (metestrus/diestrus versus proestrus/estrus) for weeks 1 and 2 using a paired-nonparametric test. The threshold for significance in all experiments was set to $p<0.05$.

\section{Results}

As illustrated in Fig. 2, G1 enhanced the breaking point for cocaine in females, but not males. A three-way repeated measures ANOVA revealed main effects of both $\operatorname{sex}\left(F_{(1,47)}=6.973 ; p=0.0112 ; n^{2} p=0.129\right)$ and timepoint $\left(F_{(1,47)}=33.14 ; p<0.0001 ; n^{2} p=0.414\right)$. Additionally, there was a significant 3-way interaction: sex $x$ treatment condition $x$ timepoint $\left(F_{(1,47)}=5.654 ; p=0.0215 ; n^{2} p=0.107\right)$. Bonferroni multiple comparisons discovered significant group differences between $\mathrm{G} 1$ treated males' and females' posttreatment $(p=0.0039)$ as well as a significant difference in breaking point between timepoints in females treated with $G 1(p<0.0001)$.

As illustrated in Fig. 3, there was no effect of prior G1 exposure on rates of extinction. A three-way repeated measures ANOVA revealed a main effect of day $\left(F_{(9,243)}=5.840 ; p<0.0001 ; n^{2} p=0.178\right)$ and a main effect of treatment condition $\left(F_{(1,27)}=4.317 ; p=0.0474 ; n^{2} p=0.138\right)$. There were two significant interactions: sex $x$ day $\left(F_{(9,243)}=2.563 ; p=0.0078 ; n^{2} p=0.087\right)$ and $\operatorname{sex} x$ treatment condition $\left(F_{(9,243)}=\right.$ $2.982 ; p=0.0022 ; n^{2} p=0.099$ ). Bonferroni multiple comparisons indicated that the $G 1$ females were significantly different from CHOL females $(p<0.0001)$ and both groups of males $(p<0.0001)$ on day 1 only. There were no group differences on any other day of extinction training between or within either sex. 
Females treated with $\mathrm{G} 1$ also exhibited greater drug-induced reinstatement than did males (Fig. 4). A twoway ANOVA revealed a main effects of treatment condition $\left(F_{(1,24)}=5.189 ; p=0.0319 ; n^{2} p=0.165\right)$ and $\operatorname{sex}\left(F_{(1,24)}=4.745 ; p=0.0394 ; n^{2} p=0.178\right)$. There was a significant sex $x$ treatment condition interaction $\left(F_{(1,24)}=4.940 ; p=0.0359 ; n^{2} p=0.171\right)$. Bonferroni multiple comparisons discovered $G 1$ treated females were significantly different than CHOL females $(p=0.0460), G 1$ males $(p=0.0241)$, and CHOL males $(p=$ 0.0259).

For females, phase of estrous cycle (metestrus/diestrus versus proestrus/estrus) had an effect on breaking point during week 1 of progressive ratio but not week 2 (data not shown). For each animal, the mean breaking point during metestrus/diestrus days was compared to the mean breaking point during proestrus/estrus days. During week 1 , proestrus/estrus was significantly greater than metestrus/diestrus $(p<0.0001)$. There was no difference between estrous cycle timepoints during week 2 of progressive ratio $(p=0.7860)$.

\section{Discussion}

We report here a sex difference in the effects of intra-DLS GPER1 activation on cocaine selfadministration. For females, activation of GPER1 enhances females' willingness to work for cocaine (i.e., breaking point), but this effect was not observed in males. Prior GPER1 activation did not alter females' or males' rate of extinction. However, females with intra-DLS GPER1 activation also show greater cocaineinduced reinstatement of drug-seeking behavior compared to control females. The effects of GPER1 activation on reinstatement in females were also not observed in males. Together, these findings indicate that E2 may be enhancing vulnerability to addiction in females, at least in part, by acting on GPER-1.

While this is the first study to show a role of GPER1 on cocaine self-administration specifically, a growing literature supports the role of E2 in regulating female behaviors related to addiction. For example, for female rodents, drug-associated cues acquire a higher incentive value when they are initially presented during estrus versus non-estrus (Johnson et al. 2019). While the current study did not investigate the association of cue-learning, we similarly report an effect of estrous cycle during initial stages of cocaine self-administration in females. During week 1 of progressive ratio testing, females show greater motivation to attain cocaine during proestrus/estrus compared to metestrus/diestrus. The lack of effect of estrous cycle in the succeeding weeks is likely due to the enhanced propensity to take cocaine overall.

We found that there were no differences in extinction rates between males and females or between prior treatment conditions beyond day 1 of extinction training. Prior studies have shown that E2 is necessary for learning and extinction of cocaine-seeking in females (Twining et al. 2013). Given that animals in the current study are gonad-intact and have circulating E2, it is not surprising that they extinguished at similar rates. It was important in the current study that animals extinguish similarly in order to compare rates of reinstatement. 
E2 enhances females' reinstatement of cocaine self-administration (Doncheck et al. 2018). This effect has previously been shown to be regulated by ER $\beta$, and not ERa, but this study was done via peripheral injections and did not investigate role of GPER1 on reinstatement (Larson and Carroll 2007). Our study supports the idea that the DLS is a target region for E2 effects on reinstatement in females.

Sex differences in drug-taking and cocaine reward are, in part, regulated by the interactions between E2 and the dopamine system (Yoest et al. 2018; Kokane and Perrotti 2020; Calipari et al. 2017). In vitro studies have shown that E2 enhances stimulated dopamine release and amphetamine-induced dopamine release in dorsal stratal tissue from female but not male rats (Becker 1990). In vivo studies showed that peripheral E2 treatment in gonadectomized rats increases cocaine-induced dopamine levels in the dorsal striatum of ovariectomized females but not castrated males (Cummings et al. 2014). Given the direct effect of intra-DLS GPER1 activation on cocaine-seeking in females seen in this study, we hypothesize that GPER1 could be, in part, modulating the effects of E2 on drug-induced DA release. Future studies should investigate this mechanism in both sexes.

In the current study, we did not see a protective effect of GPER1 activation on males' motivation for cocaine, as both G1- and CHOL-treated males show increased motivation over time. However, we have previously reported that intra-DLS GPER1 activation attenuates cocaine condition place preference in males (Quigley \& Becker 2021). Previous research that has shown that the DLS is necessary for stimulusresponse learning in males, and the current results suggest that the timing of pharmacological activation of GPER1-intra DLS, relative to initial drug exposure, is important for its effects on motivation for cocaine. (Yin et al. 2005; Yin et al. 2006). In our earlier study, GPER1 receptors in the DLS were activated or inhibited prior to the initial cocaine treatment, whereas in the current study, animals begin taking cocaine three weeks prior to administration of the GPER1 agonist. Additional studies are needed to determine whether activating GPER1 receptors intra-DLS before rats are trained to self-administer cocaine would affect the subsequent motivation and propensity to self-administer in males and females.

As discussed above, in our prior study, we reported that intra-DLS GPER1 attenuated males' preference or "liking" of cocaine. In this study we have shown that there is no effect of intra-DLS GPER1 on "wanting" cocaine in males. The neurobiological mechanisms of "liking" a drug are discrete from "wanting"; that is, one may not necessarily like a drug but crave and consume it. These dissociable mechanisms and are mediated by opioidergic and dopaminergic signaling, respectively (Robinson and Berridge 1993; Berridge 2007). We speculate that the interactions of GPER1 on opioid and dopamine signaling are different for females and males, and this could be contributing to sex dependent behavioral outcomes related to propensity to addiction.

There is circumstantial evidence for sex differences in the circuitry for "wanting" and "liking". In females, estradiol binds on GABAergic interneurons, which disinhibits dopaminergic neurons and increases dopamine levels in the striatum (Yoest et al. 2014). This enhanced neurotransmission of dopamine is presumably responsible for female's more rapid escalation of self-administration and enhanced motivation to attain psychostimulants (Cummings et al. 2014; Song et al. 2019). Directly below the dorsal 
striatum is the nucleus accumbens shell which is an opioid hedonic hotspot that regulates "liking" (Castro and Berridge 2014). In males, pharmacological studies have implicated mu-opioid receptor functioning in the shell subregion to regulate responses for palatable food and cocaine (Ward et al. 2006; Simmons and Self 2009). The direct interactions of GPER1 on $\mu$-opioid receptor function in the dorsal and ventral striatum are yet to be investigated, however, there is some evidence for crosstalk between these receptors including GPER1 activation rapidly downregulating $\mu$-opioid receptors in the arcuate nucleus as well as eliciting phosphorylation of $\mu$-opioid receptors in human neuroblastoma SH-SY5Y cells (Long et al. 2014; Ding et al. 2019).

In summary, the present study confirmed previous findings that there are sex differences related to motivation to attain drugs of abuse. As discussed above, a large body of work has supported that E2 enhances females' vulnerability towards addiction but has not necessarily unveiled which E2 receptor subtypes are responsible for the behavioral effects seen in females. The results of this study support a novel role of GPER1 in females and provides a future target for preclinical research as well as clinical research targeted at therapeutics for addiction.

\section{Perspectives And Significance}

It is vital that we better understand the neurobiological mechanisms contributing to relapse in women, given that they are more sensitive to environmental cues and more susceptible to spontaneous relapse (Quigley et al. 2021; Janes et al. 2010). Increased drug-seeking induced by E2 in females has been well established and the current study aids to this body of knowledge by identifying a role for GPER1 specifically. In this study, activation of GPER1 in the DLS not only enhances motivation for cocaine in females, but also increases drug-induced reinstatement. The information gained here may be used to target treatment for addiction via selective estradiol receptor modulators.

\section{Abbreviations}

Substance use disorder (SUD), Estradiol (E2), G-protein Coupled Estradiol Receptor 1 (GPER1), Dorsolateral Striatum (DLS), Subcutaneous (s.c.), Intraperitoneal (i.p.), Cholesterol (CHOL)

\section{Declarations}

Ethics approval and consent to participate

Not applicable

Consent for publication

Not applicable

Availability of data and materials 
Please contact first or last author for data or materials requests.

\section{Competing Interests}

The authors declare that they have no competing interests.

\section{Funding}

Funding was contributed by NIH R01-DA-039952 \& R01-DA-04979501.

\section{Authors' Contributions}

All authors had full access to all the data in the study and take responsibility for the integrity of the data and accuracy of the data analysis. Conceptualization and Methodology: Quigley, J.A. and Becker, J.B.; Investigation: Quigley, J.A., Logsdon, M.K., Graham, B.C., and Beaudoin, K.G.; Formal Analysis: Quigley, J.A.; Writing - Original Draft: Quigley, J.A.; Writing - Revision and Editing: Quigley, J.A., Logsdon, M.K., Graham, B.C., Beaudoin, K.G., and Becker, J.B.; Funding: Becker, J.B.

Acknowledgements

Not applicable

\section{References}

Back SE, Brady KT, Jackson JL, Salstrom S, Zinzow H. Gender differences in stress reactivity among cocaine-dependent individuals. Psychopharmacology. 2005;180(1):169-76.

Becker JB. Direct effect of 17 beta-estradiol on striatum: sex differences in dopamine release. Synapse. 1990;5(2):157-64.

Becker JB, Koob GF. Sex differences in animal models: focus on addiction. Pharmacol Rev. 2016;68(2):242-63.

Becker JB, Snyder PJ, Miller MM, Westgate SA, Jenuwine MJ. The influence of estrous cycle and intrastriatal estradiol on sensorimotor performance in the female rat. Pharmacology Biochemistry Behavior. 1987;27(1):53-9.

Berridge KC. The debate over dopamine's role in reward: the case for incentive salience. Psychopharmacology. 2007;191(3):391-431.

Calipari ES, Juarez B, Morel C, et al. Dopaminergic dynamics underlying sex-specific cocaine reward. Nat Commun. 2017;8:13877.

Castro DC, Berridge KC. Opioid hedonic hotspot in nucleus accumbens shell: mu, delta, and kappa maps for enhancement of sweetness "liking" and "wanting". The Journal of Neuroscience. 2014;34(12):4239- 
50.

Cummings JA, Gowl BA, Westenbroek C, Clinton SM, Akil H, Becker JB. Effects of a selectively bred novelty-seeking phenotype on the motivation to take cocaine in male and female rats. Biology of sex differences. 2011;2:3.

Cummings JA, Jagannathan L, Jackson LR, Becker JB. Sex differences in the effects of estradiol in the nucleus accumbens and striatum on the response to cocaine: neurochemistry and behavior. Drug Alcohol Depend. 2014;135:22-8.

Ding X, Gao T, Gao P, et al. Activation of the G Protein-Coupled Estrogen Receptor Elicits Store Calcium Release and Phosphorylation of the Mu-Opioid Receptors in the Human Neuroblastoma SH-SY5Y Cells. Frontiers in Neuroscience. 2019;13:1351.

Doncheck EM, Urbanik LA, DeBaker MC, et al. 17 $\beta$-Estradiol Potentiates the Reinstatement of Cocaine Seeking in Female Rats: Role of the Prelimbic Prefrontal Cortex and Cannabinoid Type-1 Receptors. Neuropsychopharmacology. 2018;43(4):781-90.

Elman I, Karlsgodt KH, Gastfriend DR. Gender differences in cocaine craving among non-treatmentseeking individuals with cocaine dependence. The American Journal of Drug Alcohol Abuse. 2001;27(2):193-202.

Grant BF, Saha TD, Ruan WJ, et al. Epidemiology of DSM-5 Drug Use Disorder: Results From the National Epidemiologic Survey on Alcohol and Related Conditions-III. JAMA psychiatry. 2016;73(1):39-47.

Jackson LR, Robinson TE, Becker JB. Sex differences and hormonal influences on acquisition of cocaine self-administration in rats. Neuropsychopharmacology. 2006;31(1):129-38.

Janes AC, Pizzagalli DA, Richardt S, et al. Neural substrates of attentional bias for smoking-related cues: an FMRI study. Neuropsychopharmacology. 2010;35(12):2339-45.

Johnson AR, Thibeault KC, Lopez AJ, et al. Cues play a critical role in estrous cycle-dependent enhancement of cocaine reinforcement. Neuropsychopharmacology. 2019;44(7):1189-97.

Kippin TE, Fuchs RA, Mehta RH, et al. Potentiation of cocaine-primed reinstatement of drug seeking in female rats during estrus. Psychopharmacology. 2005;182(2):245-52.

Kokane SS, Perrotti LI. Sex differences and the role of estradiol in mesolimbic reward circuits and vulnerability to cocaine and opiate addiction. Frontiers in Behavioral Neuroscience. 2020;14:74.

Larson EB, Carroll ME. Estrogen receptor beta, but not alpha, mediates estrogen's effect on cocaineinduced reinstatement of extinguished cocaine-seeking behavior in ovariectomized female rats. Neuropsychopharmacology. 2007;32(6):1334-45. 
Long N, Serey C, Sinchak K. 17ß-estradiol rapidly facilitates lordosis through G protein-coupled estrogen receptor 1 (GPER) via deactivation of medial preoptic nucleus $\mu$-opioid receptors in estradiol primed female rats. Horm Behav. 2014;66(4):663-6.

Lynch WJ. Acquisition and maintenance of cocaine self-administration in adolescent rats: effects of sex and gonadal hormones. Psychopharmacology. 2008;197(2):237-46.

Lynch WJ, Carroll ME. Sex differences in the acquisition of intravenously self-administered cocaine and heroin in rats. Psychopharmacology. 1999;144(1):77-82.

Martinez LA, Gross KS, Himmler BT, et al. 2016. Estradiol Facilitation of Cocaine Self-Administration in Female Rats Requires Activation of mGluR5. eNeuro 3(5).

McKay JR, Rutherford MJ, Cacciola JS, Kabasakalian-McKay R, Alterman Al. Gender differences in the relapse experiences of cocaine patients. J Nerv Ment Dis. 1996;184(10):616-22.

Quigley JA, Becker JB. 2021. Activation of G-protein coupled estradiol receptor 1 in the dorsolateral striatum attenuates preference for cocaine and saccharin in male but not female rats. Hormones and Behavior, p. 104949.

Quigley JA, Logsdon MK, Turner CA, Gonzalez I, Leonardo N, Becker JB. 2021. Sex differences in vulnerability to addiction. Neuropharmacology, p. 108491.

Richardson NR, Roberts DC. Progressive ratio schedules in drug self-administration studies in rats: a method to evaluate reinforcing efficacy. J Neurosci Methods. 1996;66(1):1-11.

Robinson TE, Berridge KC. The neural basis of drug craving: an incentive-sensitization theory of addiction. Brain Res Brain Res Rev. 1993;18(3):247-91.

Roth ME, Carroll ME. Sex differences in the escalation of intravenous cocaine intake following long- or short-access to cocaine self-administration. Pharmacology Biochemistry Behavior. 2004;78(2):199-207.

Simmons D, Self DW. Role of mu- and delta-opioid receptors in the nucleus accumbens in cocaineseeking behavior. Neuropsychopharmacology. 2009;34(8):1946-57.

Song Z, Yang H, Peckham EM, Becker JB. 2019. Estradiol-induced potentiation of dopamine release in dorsal striatum following amphetamine administration requires estradiol receptors and mGlu5. eNeuro.

Sun K, Wang F, Ma L, et al. Genetic knockout of the G protein-coupled estrogen receptor 1 facilitates the acquisition of morphine-induced conditioned place preference and aversion in mice. Biochem Biophys Res Commun. 2020;525(4):1061-7.

Twining RC, Tuscher JJ, Doncheck EM, Frick KM, Mueller D. 17ß-estradiol is necessary for extinction of cocaine seeking in female rats. Learn Mem. 2013;20(6):300-6. 
Ward HG, Nicklous DM, Aloyo VJ, Simansky KJ. Mu-opioid receptor cellular function in the nucleus accumbens is essential for hedonically driven eating. The European Journal of Neuroscience. 2006;23(6):1605-13.

Westermeyer J, Kopka S, Nugent S. Course and severity of substance abuse among patients with comorbid major depression. The American Journal on Addictions. 1997;6(4):284-92.

Yin $\mathrm{HH}$, Knowlton BJ, Balleine BW. Blockade of NMDA receptors in the dorsomedial striatum prevents action-outcome learning in instrumental conditioning. The European Journal of Neuroscience. 2005;22(2):505-12.

Yin $\mathrm{HH}$, Knowlton BJ, Balleine BW. Inactivation of dorsolateral striatum enhances sensitivity to changes in the action-outcome contingency in instrumental conditioning. Behav Brain Res. 2006;166(2):189-96.

Yoest KE, Cummings JA, Becker JB. Estradiol, dopamine and motivation. Cent Nerv Syst Agents Med Chem. 2014;14(2):83-9.

Yoest KE, Quigley JA, Becker JB. Rapid effects of ovarian hormones in dorsal striatum and nucleus accumbens. Horm Behav. 2018;104:119-29.

Zhao W, Becker JB. Sensitization enhances acquisition of cocaine self-administration in female rats: estradiol further enhances cocaine intake after acquisition. Horm Behav. 2010;58(1):8-12.

\section{Tables}

Due to technical limitations, table 1 and 2 is only available as a download in the Supplemental Files section.

\section{Figures}



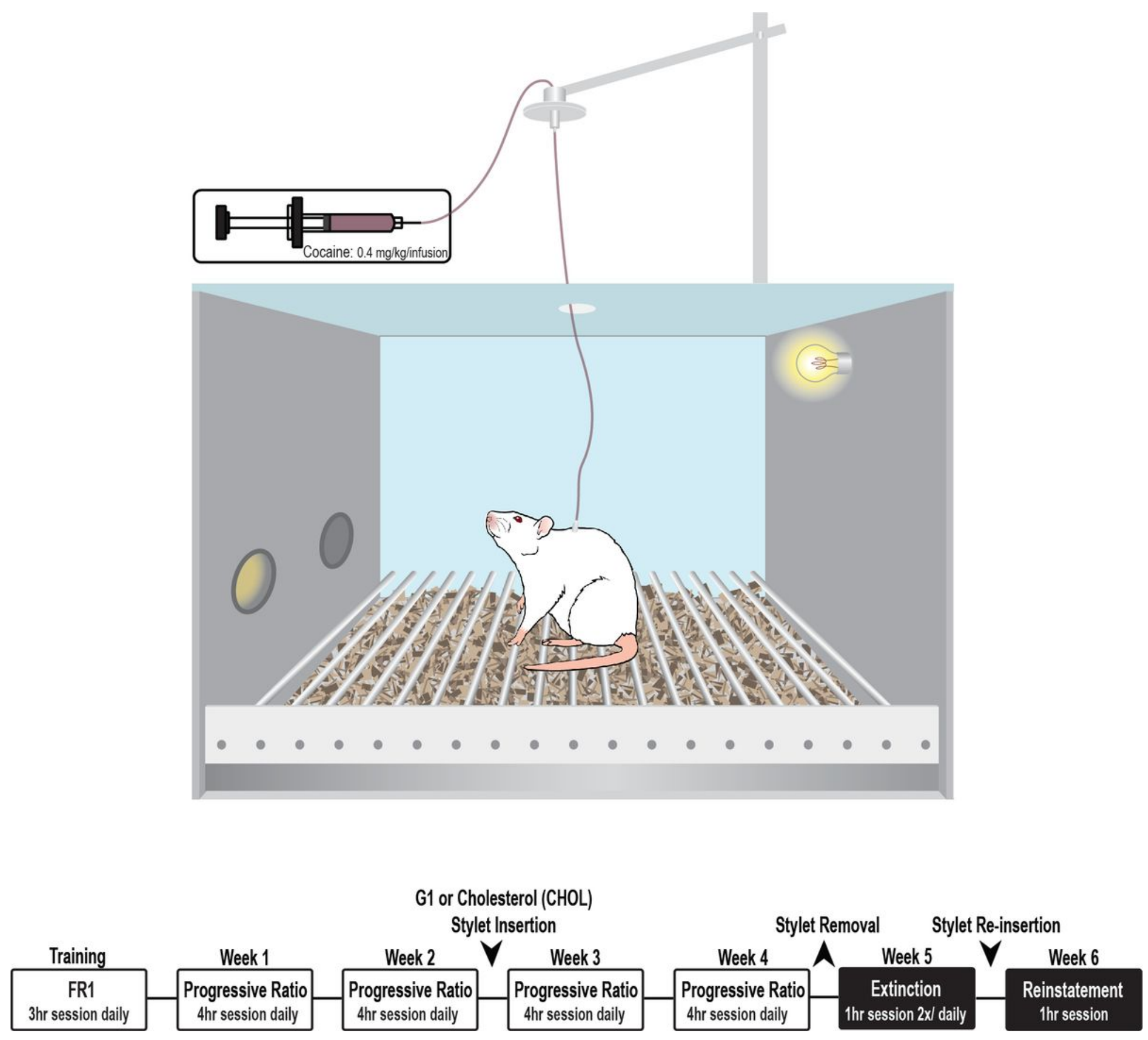

\section{Figure 1}

Illustration of self-administration operant chamber and timeline for self-administration training, progressive ratio, extinction and reinstatement testing. 


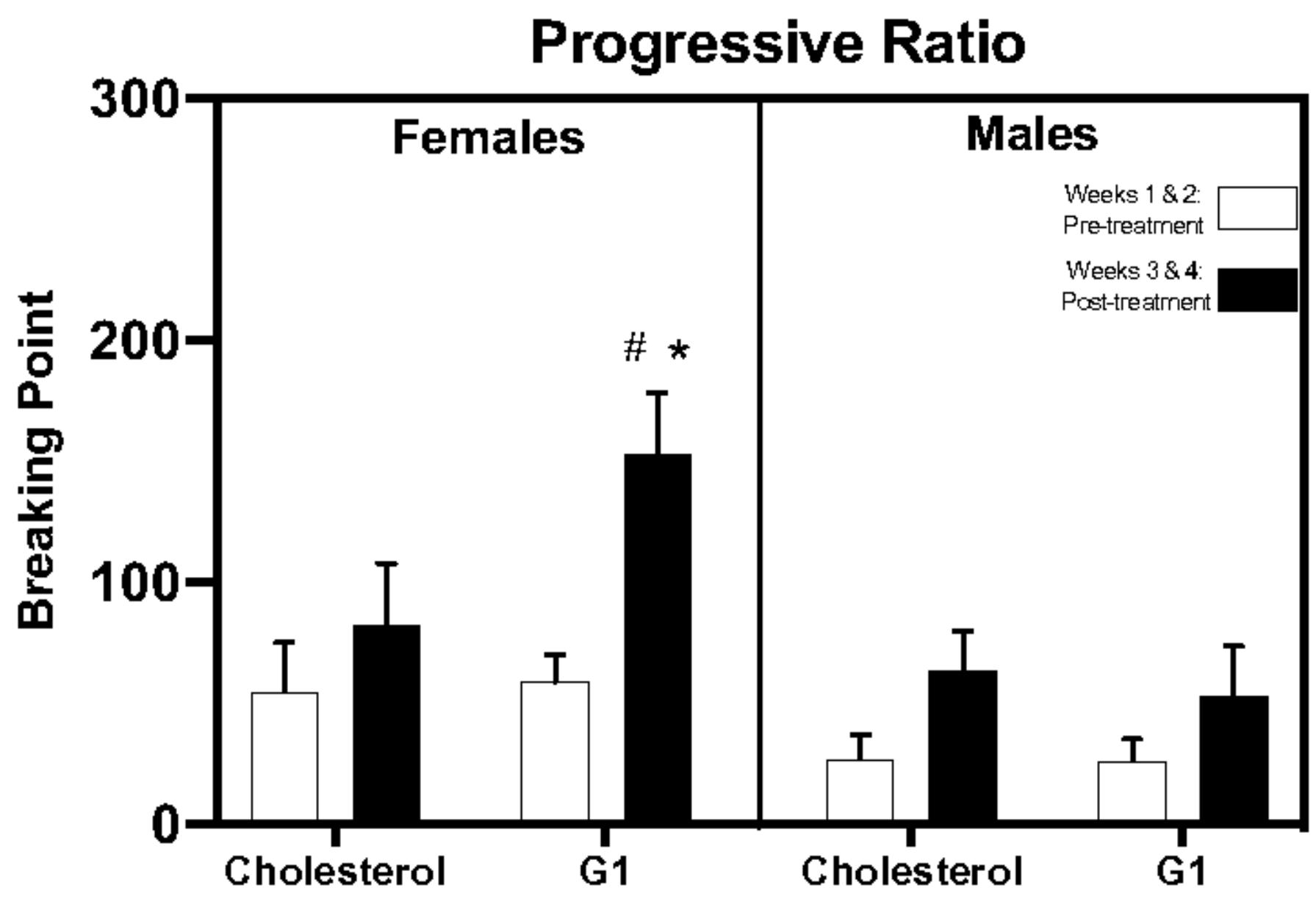

Figure 2

GPER1 activation enhances motivation for cocaine $(0.4 \mathrm{mg} / \mathrm{kg} /$ infusion) in females but not males. During weeks 3 and 4 of progressive ratio (PR), G1 treated females have significantly greater breaking point (than they did during weeks 1 and 2, prior to treatment $(p<0.0001)$. G1 treated females also have a greater breaking point than $\mathrm{G} 1$ treated males, during weeks 3 and 4 of $P R(p=0.0039)$. Data are presented as mean \pm SEM. 


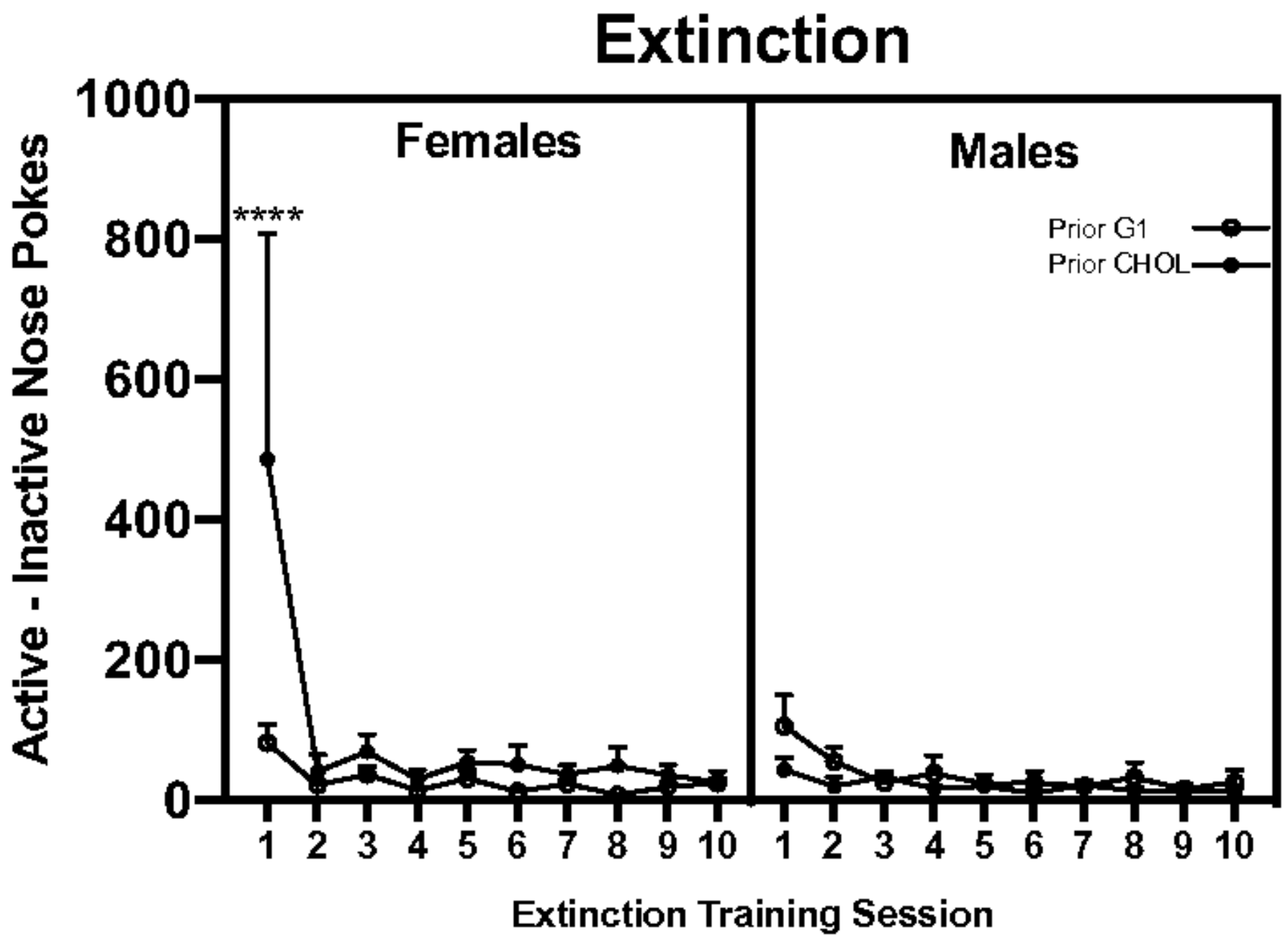

Figure 3

There is no effect of prior $\mathrm{G} 1$ treatment and no sex difference in the rates of cocaine self-administration. During the first extinction session only, prior $\mathrm{G} 1$ treated females are greater than all other groups $(\mathrm{p}<$ $0.0001)$. Data are presented as mean \pm SEM. 


\section{Reinstatement}

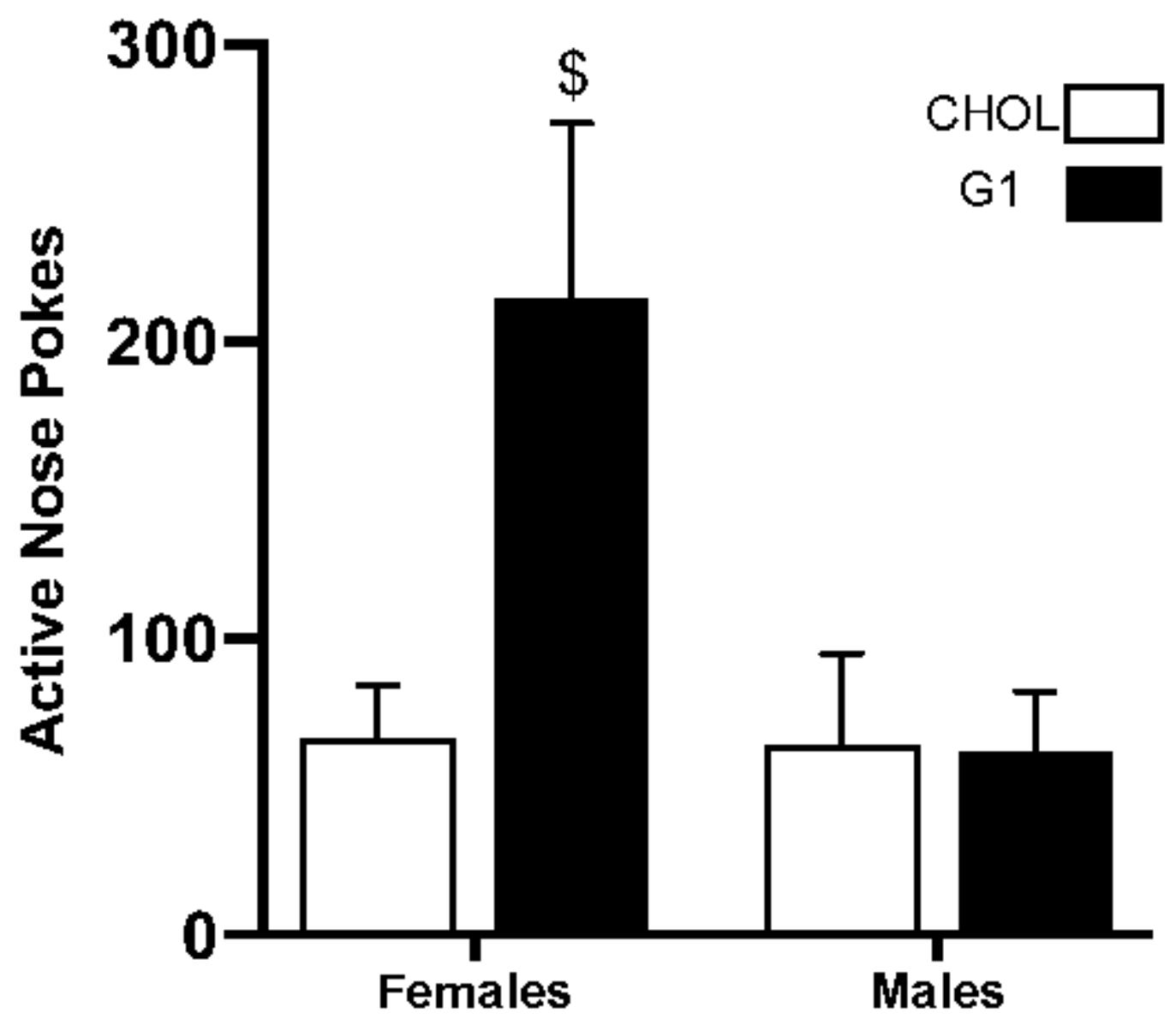

Figure 4

GPER1 activation enhances cocaine-induced reinstatement in females but not males. G1 treated females have a significantly greater number of active pokes than CHOL treated females $(p=0.0460), G 1$ males ( $p$ $=0.0241)$, and CHOL males $(p=0.0259)$. Data are presented as mean \pm SEM.

\section{Supplementary Files}

This is a list of supplementary files associated with this preprint. Click to download.

- Table1sub1SApaper.pdf

- Table2sub1SApaper.pdf 